\title{
Rosai-Dorfman disease with primary cutaneous manifestations: report of two cases
}

\section{Zina Kaddioui', Fatima Ezzehra El Fetoiki', Fouzia Hali', Farida Marnissi², Hayat Dehbi Skali', Soumiya Chiheb'}

\author{
${ }^{1}$ Service de Dermatologie, Chu Ibn Rochd, Casablanca, Morroco, ${ }^{2}$ Service d'Anatomie-Pathologique, Chu Ibn Rochd, \\ Casablanca, Morroco
}

Corresponding author: Dr. Zina Kaddioui, E-mail: zina.kaddioui@gmail.com

\begin{abstract}
Rosai-Dorfman disease (RDD), also named as sinus histiocytosis with massive lymphadenopathy, is a rare histiocytosis characterized by massive bilateral painless cervical lymphadenopathy and emperipolesis in tissue sections. We report the observation of 2 patients with a RDD, the first patient presented with cutaneous and lymph node involvement, while the other cutaneous only. The first patient was treated with methotrexate at a dose of $25 \mathrm{mg} /$ week and oral corticosteroid $1 \mathrm{mg} / \mathrm{kg} /$ day completed by excision of the cutaneous lesions with a good evolution. Topical corticosteroids was used for the second patient with partial regression. Purely cutaneous Rosai-Dorfman disease is very rare and diagnosis is difficult without any lymphadenopathy or any distinguishing features of the skin lesion. However, a high index of suspicion by clinicians and pathologists with histopathological examination of the lesion may enable a correct diagnosis be made.
\end{abstract}

Key words : Rosai Dorfman disease; Emperipolesis; Corticosteroids

\section{INTRODUCTION}

Rosai-Dorfman disease (RDD), also known as sinus histiocytosis with massive lymphadenopathy. RDD is a rare benign proliferative disorder of histiocytes in the lymph nodes with occasional extra-nodal involvement of the skin, eyes, nasal cavity, paranasal sinuses, salivary gland, pancreas, skeletal system and central nervous system. The most common site of extranodal involvement is skin, with $10 \%$ of the all patients having skin lesions [1]. However, in approximately $3 \%$ of the cases, the disease is limited exclusively to the skin [1-4]. We report 2 cases with RDD, the first patient presented with cutaneous and lymph node involvement, while the other cutaneous only.

\section{CASE REPORTS}

\section{Case 1}

A 52-year-old patient, presented with a progressive papulo-nodular eruption in the right flank and right gluteal region for 1 year. The lesions were erythematoviolaceous, infiltrated, with mammillated surfaces in places, mesuring $2 \mathrm{~cm}$ and $9 \mathrm{~cm}$ respectively. (Fig. 1). Histological examination with immunohistochemistry showed images of emperipolesis which was S100 positive and CDla negative (Fig. 2).

A PET scan, revealed polyadenopathies in the basicervical region, the mediastinum and the hiles with hypermetabolism. The anti-nuclear antibodies (ANA) was positive. The patient was treated with thalidomide $100 \mathrm{mg} /$ day, in the absence of improvement, methotrexate at a dose of $25 \mathrm{mg} /$ week was started with a slight improvement. The management was completed by excision of the cutaneous lesions with a good evolution and the addition of a oral corticosteroid $1 \mathrm{mg} / \mathrm{kg} /$ day (Fig 3). The patient is stable until now.

\section{Case 2}

A 47-year-old woman, had for 1 year, 2 nodular lesions on an erythematous plaque in her back. The clinical

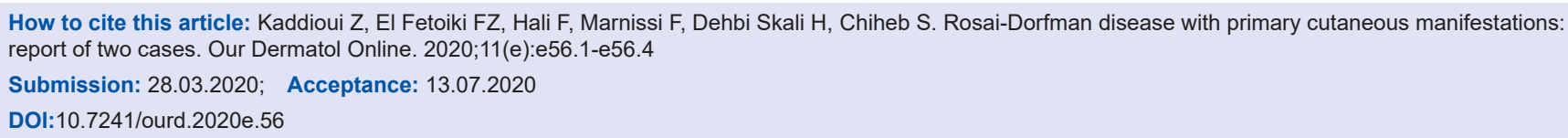


examination found two erythematous nodules, with presence of satellites papular lesions (Fig. 4). The histological study with IHC confirmed the diagnosis. Laboratory tests and radiologic assessement were negative. For esthetic reason and the significant size of the lesion, a super high potency topical corticosteroids was used with partial regression.

\section{DISCUSSION}

RDD has mainly 2 forms: one affecting lymph nodes and rarely other organs with systemic manifestations and the other purely cutaneous form without systemic or nodal disease, even with long-term follow-up $[5,6]$. This case reports presents the two forms.

The exact etiology of systemic and cutaneous RosaiDorfman disease is unknown, but in many case reports and small studies, the laboratory findings suggest an immune dysfunction to an antigen or infectious organism. The most frequently described infections are human herpes virus (HHV6) infection [1,7],

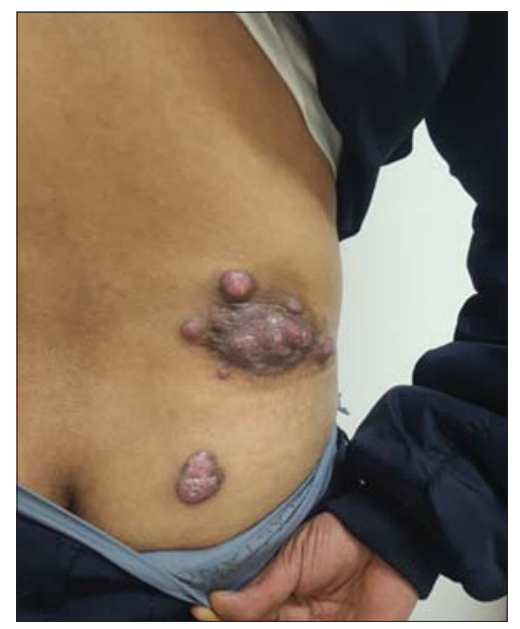

Figure 1: Lesions erythemato-violaceous, infiltrated, with mammillated surfaces in places, measuring $2 \mathrm{~cm}$ and $9 \mathrm{~cm}$ respectively.

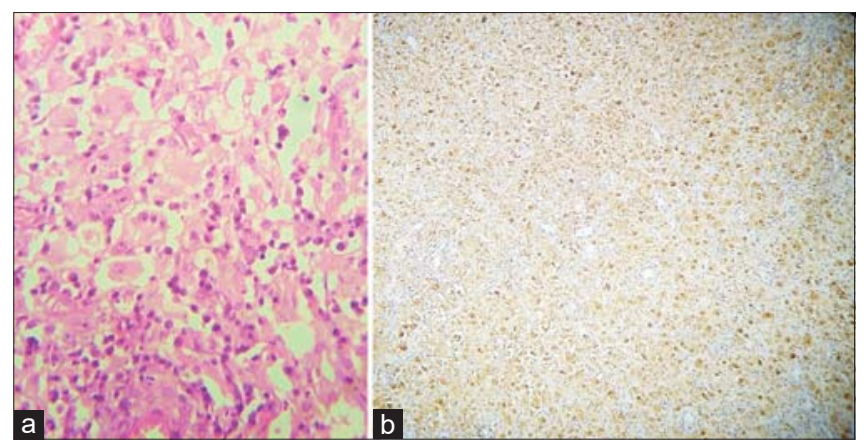

Figure 2: Images of emperipolesis which was $\mathrm{S} 100$ positive (a) and CD1a negative (b).
Epstein-Barr virus [8], infection, HIV positivity [8], varicella and herpes zoster [9], RDD has also been associated with immune abnormalities including uveitis [10], systemic lupus erythematosus [11] and autoimmune haemolytic anaemia [12] in some patients.

Most common site of cutaneous involvement is the facial area, followed by trunk, ear, neck, upper and lower extremities, and genitals $[13,14]$.

Clinical features are usually characterized by the combination of papules, plaques, or nodules and pustules, granuloma annulare-like, psoriasiform, rosacea-like, xanthelasma-like, acneiform, vasculitislike, and pseudotumor- like lesions $[6,8,15,16]$. One of the most common type of lesions is central nodulo plaque with surrounding satellite papules. Skin discoloration is also seen with erythematous brownish, gray-blue, violaceous, or yellowish hue appearance.

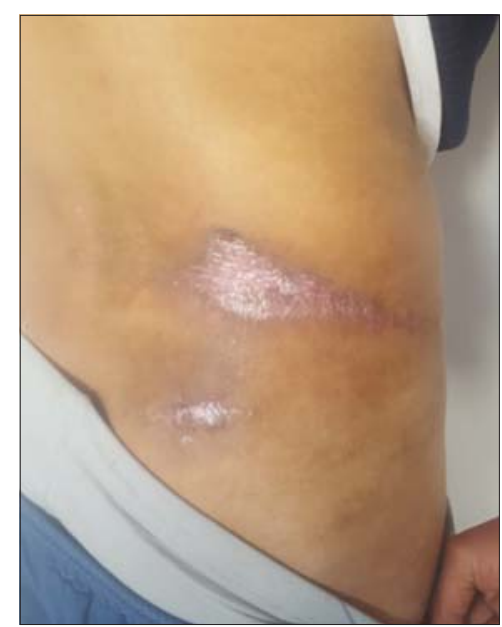

Figure 3: Good evolution of the lesions after excision.

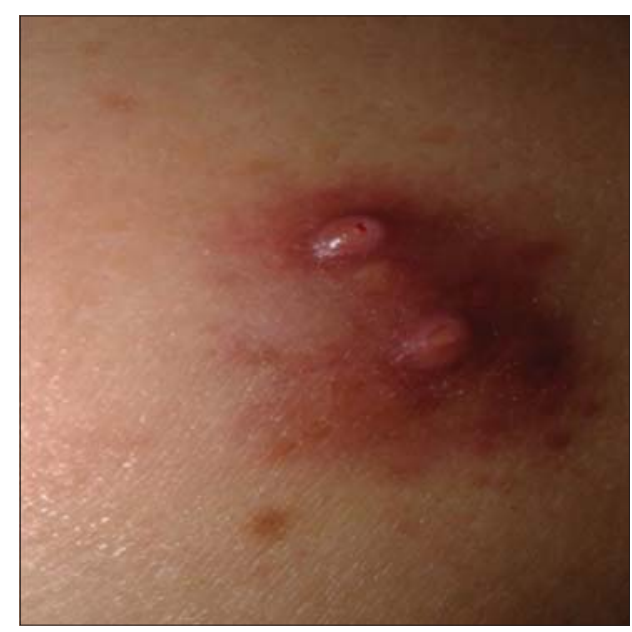

Figure 4: Two erythematous nodules, with presence of satellites papular lesions. 
Ulceration, superficial scaling, or infiltration of lesions into deeper dermis can cause functional or esthetic problems. In our cases, the first one had papulo-nodular eruption erythemato-violaceous and the second one two erythematous nodules, with presence of satellites papular lesions.

Systemic symptoms (fever, malaise), anaemia, raised erythrocyte sedimentation rate $(\mathrm{ESR})$ and immunological abnormalities commonly seen in systemic RDD. Systemic form of the disease principally affects children and young adults with a median age at onset of 20.6 years, whereas cutaneous form is more common in elderly women, with a median age at onset of 43.5 years. People of white ethnicity and Asians are dominantly affected $[13,14]$. Our first patient is medium brown skin and male with positive ANA test.

Lymph node involvement alone is found in $57 \%$ of patients. Multiple, painless cervical lymphadenopathy is the most frequent initial symptom of the disease, seen in almost $90 \%$ of the cases [17]. In our patients, there was no palpable lymphadenopathy but detected in first cas during imaging studies .

The definitive diagnosis of pure cutaneous RDD requires histological examination. Histological findings in cutaneous RDD are similar in all involved locations. This is characterized by dense histiocytic infiltrates with plasma cells and lymphocytes. The large histiocytes (Rosai-Dorfman cells) have vesicular nuclei with indistinct cell borders. They exhibit the phenomenon of emperipolesis. These histiocytes are strongly reactive for S- 100 protein and variably positive for CD68 but are negative for CDla. In both patients, RDD was confirmed by histological study with immunohistochemistry

The clinical course of RDD is usually benign and selflimited, especially in those presenting with localized lymph node involvement. For most cases, no treatment is necessary as spontaneous resolution is observed over 1-3 years [18]. We treat if the lesions persist for longer periods of time or the are cosmetically unacceptable.

The optimal duration of steroids or other systemic therapies for RDD is not known. Six to 12 months of systemic therapy followed by observation, assuming tolerance and a favourable response to treatment, is a reasonable approach [19]. Data are insufficient to characterize the prognosis of RDD in great detail.
Patients with multifocal and extranodal RDD, particularly those with kidney, liver or lower respiratory tract disease, appear to have an unfavorable prognosis. One of our patients received systemic corticosteroid therapy because he had cutaneous and lymph node involvement, and the second was treated with topical corticosteroids because he had just a cutaneous RDD. They are still being followed with good evolution.

\section{REFERENCES}

1. Pitamber HV, Grayson W. Five cases of cutaneous Rosai-Dorfman dis- ease. Clin Exp Dermatol. 2003;28:17-21.

2. Chaoui R, Baybay H, El Kadiri S, Douhi Z, Elloudi S, Mernissi FZ, et al. Adult-onset xanthogranuloma. Our Dermatol Online. 2020;11:e17.1-e17.3.

3. Terrero D, Valdebran M, Xue R. Long-standing asymptomatic pretibial patch. Our Dermatol Online. 2016;7:230-1.

4. Diallo M, Touré M, Diatta BA, Diop A, Ndiaye M, Diop MT, et al. [Rosaï-Dorfman disease with tumoral skin lesions]. Our Dermatol Online. 2017;8(suppl. 1):40-3.

5. Molina-Garrido MJ, Guillén-Ponce C. Extranodal Rosai Dorfman disease with cutaneous and periodontal involvement: a rare presentation. Case Rep Oncol. 2011;4:96-100.

6. Fening K, Bechtel M, Peters S, Zirwas M, Darabi K. Cutaneous Rosai-Dorfman disease persisting after surgical excision: report of a case treated with acitretin. J Clin Aesthet Dermatol. 2010;3:34-6.

7. Scheel MM, Rady PL, Tyring SK, Pandya AG. Sinus histiocytosis with massive lymphadenopathy: presentation as a giant granuloma annulare and detection of human herpesvirus 6. J Am Acad Dermatol. 1997;37:643-6.

8. Pitamber HV, Grayson W. Five cases of cutaneous Rosai-Dorfman disease. Clin Exp Dermatol. 2003;28:17-21.

9. Raquena L, Kutzner H, Escalonilla P, Ortiz S, Schaller J, Rohwedder A. Cutaneous reactions at sites of herpes zoster scars: an expanded spectrum. Br J Dermatol. 1998:138:161-6.

10. Srinivasan SM, Parthasarathy S. Cutaneous Rosai-Dorfmans nodules on cheek. Our Dermatol Online. 2016;7:319-22.

11. Brenn T, Calonje E, Granter SR, Leonard N, Grayson W, Fletcher CDM, et al. Cutaneous Rosai-Dorfman Disease is a distinct clinical entity. Am J Dermatopathol. 2002;24:385-91.

12. Grabczynska SA, Toh CT, Francis N, Costello C, Bunker CB. RosaiDorfman disease complicated by autoimmune haemolytic anaemia: case report and review of a multisystem disease with cutaneous infiltrates. Br J Dermatol. 2001;145:323-6.

13. Eiras Jda C, Schettini AP, Lima LL, Tubilla LH, Oliveira RM. Cutaneous Rosai-Dorfman disease: a case report. An Bras Dermatol. 2010;85:687-90.

14. Wang JT, Palme CE, Wang AY, Morgan GJ, Gebski V, Veness MJ. In patients with metastatic cutaneous head and neck squamous cell carcinoma to cervical lymph nodes, the extent of neck dissection does not influence outcome. J Laryngol Otol. 2013;127(Suppl 1):S2-7.

15. Ortonne N, Fillet AM, Kosuge H, Bagot M, Frances C, Wechsler J. CutaneousDestombes-Rosai-Dorfman disease: absence of detection of HHV-6 and HHV-8 in skin. J Cutan Pathol. 2002;29:113-8.

16. Shi XY, Ma DL, Fang K. Cutaneous Rosai-Dorfman disease presenting as a granulomatous rosacea-like rashs. Chin Med J (Engl). 2011;124:793-4.

17. Kutlubay Z, Bairamov O, Sevim A, Demirkesen C, Mat MC. Rosai-Dorfman disease: a case report with nodal and cutaneous involvement and review of the literature. Am J Dermatopathol. 2014;36:353-7. 
www.odermatol.com

18. Mebazaa A, Trabelsi S, Denguezli M, Sriha B, Belajouza C, Nouira R. Extensive purely cutaneous Rosai-Dorfman disease responsive to acitretin. Int J Dermatol. 2007;46:1208-10.

19. Abla O, Jacobsen E, Picarsic J, Krenova Z, Jaffe R, Emile J-F, et al. Consensus recommendations for the diagnosis and clinical management of Rosai-Dorfman-Destombes disease. Blood. 2018;131:2877-90.
Copyright by Zina Kaddioui, et al. This is an open access article distributed under the terms of the Creative Commons Attribution License, which permits unrestricted use, distribution, and reproduction in any medium, provided the original author and source are credited.

Source of Support: Nil, Conflict of Interest: None declared. 